\title{
Publisher Correction: A 51,000-year-old engraved bone reveals Neanderthals' capacity for symbolic behaviour
}

Dirk Leder (D), Raphael Hermann (D), Matthias Hüls, Gabriele Russo (D), Philipp Hoelzmann, Ralf Nielbock (D), Utz Böhner, Jens Lehmann, Michael Meier, Antje Schwalb, Andrea Tröller-Reimer, Tim Koddenberg (iD) and Thomas Terberger

Correction to: Nature Ecology \& Evolution https://doi.org/10.1038/s41559-021-01487-z, published online 5 July 2021.

In Fig. 2 of this Article originally published, in square 97/297 a yellow rectangle was mistakenly placed beneath bone 6. This error has now been corrected.

Published online: 20 July 2021

https://doi.org/10.1038/s41559-021-01537-6

๑ The Author(s), under exclusive licence to Springer Nature Limited 2021 